\title{
Performance of Critical Thinking and Existence of Logical Fallacies in Indonesian Varsity English Debate 2020 in Jakarta
}

\author{
Muhammad Zulfikar Faishol Ali ${ }^{1}$, Abdurrachman Faridi ${ }^{2}$, Zulfa Sakhiyya ${ }^{3}$ \\ ${ }^{1}$ Student of English Department, Department of Semarang State University \\ ${ }^{2}$ Lecture of English Education Department of Semarang State University \\ ${ }^{3}$ Lecture of English Education Department of Semarang State University
}

Corresponding e-mail: muhammadzulfikarfaisholali@gmail.com

DOI: 10.29322/IJSRP.11.01.2021.p10980

http://dx.doi.org/10.29322/IJSRP.11.01.2021.p10980

\begin{abstract}
This study is to analyze the types of critical thinking skills are performed by the debaters, logical fallacies are made by the debaters, and the debaters' responses using critical thinking skills to the opponents' logical fallacies in debate. The writer chooses the topic of the study because debate contains critical thinking and logical fallacies. The object of this study is college students in IVED 2020. The result of this study shows that there are six types of critical thinking skills are used in the debate (Fisher, 2001). The finding shows that most of the critical thinking skills performed in debate competition by debaters. The findings show debaters fulfil all components of critical thinking skills. Mayfield' theories (2007) are used to analyze logical fallacies that exist in debate. The analysis on the logical fallacies results shows that appeal to fear, word ambiguity, appeal to prejudice, hasty generalization, false cause, appeal to pity, red hearing, and false analogy existed in debate (Mayfield, 2007). However, the debaters only respond to a few logical fallacies. The logical fallacies that are responded by debaters are appeal to fear, false cause, appeal to prejudice, and hasty generalization. Moreover, debaters respond fallacies used critical thinking skills. Critical thinking skills that are used by debaters are, 1) identifying and evaluating assumptions, 2) identifying the elements in a reasoned case, especially reasons and conclusions, 3) clarifies and interprets expressions and ideas, and 4) analyze, evaluate, and produce explanations. 5) drawing inferences. 6) evaluating arguments of different kinds.
\end{abstract}

Index Terms- critical thinking, logical fallacy, debate

\section{INTRODUCTION}

Recently, critical thinking is one of the mostly discussed skills. A recent research conducted by Educational Testing Service (Liu, Frankel, \& Roohr, 2014) that interviewed provost from more than 200 institutions regarding the most commonly measured general education skills reveals that critical thinking was one of the most frequently mentioned competencies considered essential for both academic and career success. Critical thinking is one of the skills students need in the $21^{\text {st }}$ century (Rotherham \& Willingham, 2010). In addition, Soffel (2016) through World Economic Forum on the future of job report reveal that critical thinking was number 4 from 10 skills to be mastered by students in the $21^{\text {st }}$ century in 2015. It is predicted that in 2020 it will rise to number two. CasnerLotto \& Barrington (2006) found that among 400 surveyed employers, $92.1 \%$ identified critical thinking as a very important skill to be taught and mastered by 4-year college graduates to be successful in today's workforce. This completely shows the value of critical thinking. Thus, it can be seen that critical thinking is a very important skill to be taught and mastered by students.

Critical thinking is a cognitive activity, associated with using the mind. Learning to think in critical analytic and evaluate ways means using mental processes such as attention, categorization, selection, and judgment. Hence, critical thinking is a scientific process of deciding what to believe or do. It means making reasoned judgments in order to focus on deciding what to believe or do. The "Reasoned" word means that it (the reason) produced by consider logical thinking process, and "Judging" consists of determining the degree to which a thing meets a standard, a rule, or other criteria (Ennis, 1985; Beyer, 1995; Facione, 2000; Stapleton, 2001). It involves logical thinking, decision making, and problem-solving process (Halpern, 2003; Butler, 2012).

Critical thinking has strong relation with the debate. Meanwhile, Freeley \& Steinberg (2009) define debate as the process of advocacy and inquiry, a way of arriving at a reasoned judgment on a proposition. Teaching critical thinking through debate allows for collaboration where teams can achieve higher levels of thinking through the use of persuasive evidence (Freeley \& Steinberg, 2009).

This publication is licensed under Creative Commons Attribution CC BY.

http://dx.doi.org/10.29322/IJSRP.11.01.2021.p10980

WWW.ijsrp.org 
Rather than lecturing, students learn more advanced by actively analyzing, discussing, and applying content in meaningful ways. Furthermore, the debate requires all students to actively engage in the multidimensional teaching and learning of topic area (Omelicheva \& avdeyeva, 2008). Moreover, debate is better suited for enhancement of critical thinking skills than traditional techniques such as lecturing (Roy \& Macchiette, 2005).

In addition, Goodwin (2003) has investigated the students' perception toward debate. Debate is an oral communication process which is used to defend argument. Every individual in debate will argue or give arguments in certain way, so that the interlocutor will agree his/her argument. This obviously shows, this type of public speaking is not merely about fluency but also ability in conveying the arguments to the judges.

Debate is not only being learnt in formal class but also in organization which focus on debating to join competition in order to create achievements. The ability of constructing a good argument relies on the ability to make a good logical construction. It can be inferred that a good argument also has a good logical construction. While good logical construction can be reached by avoiding the logical fallacy, because the existence of fallacy can be interpreted as lack of logical construction. Johnson \& Blair (2006) claim that a fallacy is an error in reasoning and has a negative effect on the assessment of an argument's quality. Fallacious arguments are very common and can be quite persuasive, at least to the casual reader or listener.

How the fallacious are existed in debate, Mayfield (2014) argues that There are four types of logical fallacy that commonly happen: 1) manipulation through language, 2) manipulation through emotions, 3) manipulation through distraction, and 4) inductive fallacy. While, to know critical thinking are performed in debate Fisher (2001) classifies into many types such as, 1) identifying the elements in a reasoned case, especially reasons and conclusions, 2) identifying and evaluating assumptions, 3) clarifying and interpreting expressions and ideas, 4) evaluating arguments of different kinds, 5) analyzing, evaluating and producing explanations, 6) drawing inferences, and 7) producing arguments.

This research focuses on the EFL students' critical thinking and logical fallacies in English debates. While, There are number of previous studies conducted by other researchers related to this study. The first publication was written by Goodwin et al. (2003). This study focused on performance of the students worked in teams to face issues arising from reading and lecture to present debate. The group then presented debate. The judges are other students who were not involved in the debate. Moreover, those who were not involved in the debate also writes a brief essay expressing their views. The result of this study is divided into two sides. First, some students reported that debate technique was uncomfortable or unfamiliar. Second, most of the students expressed that debate was very helpful in mastery content or gaining knowledge through analyzing arguments. They bear in mind that debate encounters them to be open-minded to the different kinds of opinions and it improved their critical thinking skills.

The second paper came from Virginia (2017), this report highlighted there were several types of logical fallacy found. They were problematic premise, red hearing fallacy, irrelevant reason, two wrong fallacy, begging the question, fault analogy, and fallacy incompatibility. Moreover, some factors that caused the debaters create fallacy are the Level of understanding toward concept of logical fallacy, lack of reading and amount of debate practice.

Thus, it is very important to avoid any fallacy on the argumentation. Moreover, logical fallacy takes important role to assess quality of argument especially on debate field because debaters have been compelled to build a good quality of argument in order to give maximum performances. However, there is not yet found a research related to critical thinking and logical fallacy in debate. Therefore, it becomes the reason of the researcher to conduct a study related to critical thinking and logical fallacy in debate.

\section{RESEARCH ELABORATION}

This study uses a descriptive method by applying the qualitative analysis with the specialization on the descriptive study. It deals with the objectives of this research. In descriptive research, there is no tendency for manipulating the data, because the writer has no control over the variable. The research uses a descriptive qualitative method. In this research, the problem is identified based on trends in the field or on the need to explain why something occurs.

The object of the study is the utterances of English debate competition performed by the debaters in Grand Final National University Debate Competition 2019. Afterwards, it is to analyze the role of debating activity to EFL students' critical thinking skills and logical fallacy shown by the EFL students who participate in IVED 2020. The subject of this research is as many as two groups or about six participants. Slightly people like debate because it requires good speaking, analyzing, bravery, etc. Also, it is not stated taught in whole subjects from one to six semester.

a. Critical thinking skills performed by debaters

\section{FINDING AND DISCUSSION}

The videos are analyzed to seek out the kinds of critical thinking skills performed by debaters in English debate. The critical thinking skills are proposed by Fisher (2001). In this part, the writer analyzed some components of critical thinking such as, identifying the elements in a reasoned case, especially reasons and conclusions, identifying and evaluating assumptions, clarifying and interpreting expressions and ideas, evaluating arguments of different kinds, analyzing, evaluating and producing explanations, drawing inferences, and producing arguments.

i. Identifying the elements in a reasoned case, especially reasons and conclusions

The debate performed by debaters in Grand Final IVED 2020. The duration of this video recording was around one hour thirteen minutes. The findings are analyzed by using indicator words, containing reasons and conclusions proposed by Fisher (2001). 
Debaters used two kinds of indicator words, the first is cardinal number like 'first' (e.g findings \#1, \#4), 'second' (e.g finding \#104), 'because' (e.g. in findings \#2, \#3. \#6) and the second is indicator words signaling reasons like 'so' (e.g in findings \#112, \#113, \#114), 'hence' (e.g in finding \#119, \#120)', and 'therefore' (e.g findings \#132, \#133, \#139).

ii. Identifying and evaluating assumptions

In findings \#152, there is a belief that the debater is taken for granted. The belief that the debater 'takes for granted' is called an assumption. Moreover, the sense in which it is believed and accepted or 'taken for granted' by a speaker or writer is not stated or made explicitly. In general, it is also called an assumption (Fisher, 2001). On the sentence above, the debater tried to bring stoicism as a solution for impoverished people. It is supported by the last sentence 'if impoverished people express their pain or their sadness, their regret, it will lead them to nowhere.' In finding\#153, there is an implies meaning that debater wants to deliver. It is 'impoverished people cannot get a proper school in view of government does not give them.' The use of 'but' in sentence \#153 indicates that the real meaning is the opposite of the debater stated. In finding \#154, the debater tried to relate stoicism into the emotional stability terms

iii. Clarifying and interpreting expressions and ideas

Fisher (2001) asserted five ways to clarify terms and ideas by: (a) giving another expression which has much similar meaning or paraphrase, (b) doing point (a) in very precise terms by giving another expression which has precisely the same meaning, (c) giving examples (and non-examples), (d) drawing contrasts, (e) and describing the history of an expression.

According to the five ways to clarify the term and the ideas, the speaker used point (a) about giving another expression which has similar meaning or paraphrase to clarify the stoicism by saying 'Stoicism means that is the endurance of pain.......'. In findings \#160 and \#161, the speaker gave clear comprehension about the debate motion. Moreover, the debater used point (b) about giving another expression with very precise term to clarify the stoicism. In finding \#163 that is saying 'Government always try to change the system for example the for the sake of to simplify so that's why all the facilitated that to try to provide for the society can be more accessible to the society, ladies and gentlemen'. They try to simplify the administration process for example, so it is why even impoverished communities are even not understanding about the structure.' debater tried to make the ideas 'the government do the best to provide public services for the society' clear. According to the five ways to clarify the expressions, terms and ideas, debater used point (c) about giving examples in order to make the audience comprehension about 'public services' clearer. As shown in Finding\#165.

iv. Evaluating arguments of different kinds

Finding \#168 is categorized as value judgement. It can be seen in the sentence 'it will lead them to nowhere' that it is clear assessing something bad. Finding \#170 is categorized into causal claim. As the word 'causal' is used on its term, there are a reason and conclusion that could not be analyzed by using indicator words but it is simply understandable. In addition, finding \#169, \#172, \#173, \#177 are categorized into recommendation since the word 'should' is exist in the sentence as the indicator word signaling recommendation.

v. Analyzing, evaluating and producing explanations

Based on finding \#187, the main topic refers to impoverished people. Sentence 'they will just focus on blaming the system' is about impoverished people case. The second sentence indicates that the writer evaluated the case. it is supported by the statement 'While, in the status quo government already provide them free education, free healthcare, opened up fields and so on so forth'.

vi. Drawing inferences

To challenge the inference, Fisher (2001) reveals that if the reason compels you to accept the conclusion, then the inference works. debater seemed not working well with the inferences. Because the reason seems not encounter the acceptance of the conclusion.

In finding \#191, the inference is the move from 'And the only way to get that is they have to work hard; they need to earn money ladies and gentlemen, ' to 'we believe that by complaining will not going to lead these impoverished people to a better life'. In finding \#192, the inference is the move from 'In their side it will be better because stoicism condition will create unconducive community ...' to 'that over beyond your capability'. Therefore, the inference is the move from 'So that is why...' to 'it's still giving a better survivability.'

vii. Producing arguments

Arguments happen when the author try to persuade the audience or the reader that the conclusion is true (Fisher, 2001). In finding \#198, debater tried to persuade the audience or the listener that 'when you are complaining you will start the mind set in your mind like you are not enough in this kind of particular situation'. It is supported by providing a statement 'Complaining will make you productive...'. Also, debater provided second statement supported the first statement that put after 'hence' word. It is 'you want to change those situations...' Then, the conclusion appears 'When you want to change the situation, you want to be better, you want to be more productive.

b. Logical Fallacies Exist in Debate

There are four categories of fallacies and there are totally twenty types of fallacies. After analyzing the data, it was found that debaters made a number of fallacies that belong to the four categories. Of all the twenty types of fallacies, only eight types of fallacies were found. This research is descriptive research because the data in this research were analyzed in the form of description and explanation. However, quantitative calculation was still used in a small number to support and strengthen the result of the descriptive 
analysis. The frequency and percentage of the twelve types are shown in the following table. Referring to the classification by Mayfield (2007), the followings are some of the fallacies produced by debaters in their arguments:

Table 1. The Types of Fallacies Made by Debaters

\begin{tabular}{|l|l|l|l|l|}
\hline Categories of Fallacies & No. & Types of Fallacies & F & $\%$ \\
\hline Manipulation through language & 1 & Word Ambiguity & 4 & $18 \%$ \\
\hline \multirow{3}{*}{ Manipulation Through Emotion } & 2 & Appeal to fear & 6 & $26 \%$ \\
\cline { 2 - 5 } & 3 & Appeal to pity & 2 & $9 \%$ \\
\cline { 2 - 6 } & 4 & $\begin{array}{l}\text { Appeal to Prejudice / Ad } \\
\text { Hominem }\end{array}$ & 3 & $13 \%$ \\
\hline Manipulation Through Distraction & 5 & Red Herring & 1 & $4 \%$ \\
\hline Inductive Fallacy & 6 & Hasty Generalization & 3 & $13 \%$ \\
\cline { 2 - 6 } & 7 & False Analogy & 1 & $4 \%$ \\
\cline { 2 - 6 } & 8 & False Cause & 3 & $13 \%$ \\
\hline
\end{tabular}

From the table above, it can be seen that there are four categories of fallacies. The second category appeared with the highest number of types of fallacies. There are three types out of eight namely, (1) word ambiguity, (2) appeal to fear, (3) appeal to pity, (4) appeal to prejudice, (6) hasty generalization, (7) false analogy, (8) false cause. In the third category, there was only one type found. Furthermore, the third category, manipulation through distraction, appeared with the least types of fallacies, that is only one; red herring. With regard to the type occurrences, the fallacy of appeal to fear appeared with the highest frequency of 6 occurrences (26\%). They are followed by the fallacy of wrong ambiguity that appeared as the second highest frequency of 4 occurrences (18\%). Then, the fallacy of appeal to prejudice (13\%), hasty generalization (13\%), and false cause (13\%) came up with the less frequency of only 3 occurrences. Interestingly, the fallacy of appeal to pity appeared only 2 occurrences (9\%). And the rest, red herring (4\%) and false analogy (4\%) appeared with the least frequency of only 1 occurrence

c. Debaters respond to logical fallacies using critical thinking skills

The debater responds to the logical fallacies using critical thinking skills by identifying and evaluating assumptions by stating, "the government side of the house say that complain will make you hard to find the job we say no these kinds of particular things will not happen." followed by identifying the elements in a reasoned case, especially reasons and conclusions. It is showed in the sentence "because when you are for example you are in the job field, for example, "you will not tell for example the one that does what do you not for example tell the manager that for example, you have a bad feeling."

Additionally, debater clarifies and interprets expressions and ideas by giving example, "for example you will not tell the one that does what do you not tell the manager that you have a bad feeling so on and so forth." Furthermore, the debater also analyzes, evaluates, and produces explanations by stating "but you will tell your feeling to those particular persons that you feel you are comfortable with..."

\section{CONCLUSION}

Based on the analysis in previous chapter, three aspects are concluded in this research. The aspects are: (1) the kinds of critical thinking skills performed in debate competition (2) logical fallacies exist in debate competition, and (3) debaters' respond to logical fallacies using critical thinking skills in the debate competition. This research involved six respondents using purposive sampling. The finding shows that most of the critical thinking skills performed in debate competition. The findings showed debaters fulfill all components of critical thinking skills. Therefore, English debate is good to teach and encounter critical thinking skills. Meanwhile, there are several types of logical fallacies that were found in the argumentation made by debaters during the debate competition. The logical fallacy that occurs on argumentation made by debaters are appeal to fear, word ambiguity, appeal to prejudice, hasty generalization, false cause, appeal to pity, red hearing, and false analogy. However, the debaters only respond to a few logical fallacies. The logical fallacies that are responded by debaters are appeal to fear, false cause, appeal to prejudice, and hasty generalization. Moreover, debaters respond fallacies use critical thinking skills. Critical thinking skills that are used by debaters are, 1) identifying and evaluating assumptions, 2) identifying the elements in a reasoned case, especially reasons and conclusions, 3) clarifies and interprets expressions and ideas, and 4) analyze, evaluate, and produce explanations. 5) drawing inferences. 6) evaluating arguments of different kinds.

\section{REFERENCES}

Casner-Lotto, J., \& Barrington, L. (2006). Are They Really Ready to Work? Employers' Perspectives on The Basic Knowledge and Applied Skills of New Entrants to The $21^{\text {st }}$ Century U.S. Workforce. Partnership for $21^{\text {st }}$ Century Skills.

Ennis, R. H. (1989). Critical Thinking and Subject Specificity: Clarification and Needed Research. Educational Researcher, 18(3), 4-10. https://doi.org/10.3102/0013189X018003004

Fisher, A. (2001). Critical Thinking: An Introduction ( $\left.2^{\text {nd }} e d\right)$. Cambridge University Press. 


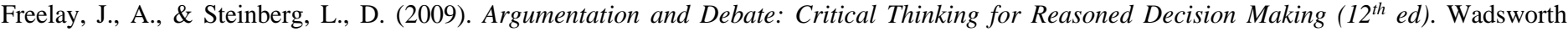
Cengage Learning.

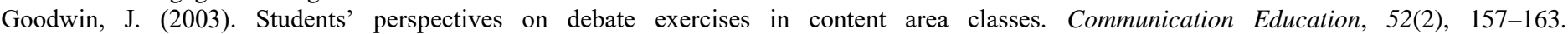
https://doi.org/10.1080/03634520302466

Halpern, D. F. (2003). Thought and knowledge: An Introduction to Critical Thinking. Erlbaum.

Johnson, R.H., \& Blair, J. A. (2006). Logical Self-Defense. Idebate Press.

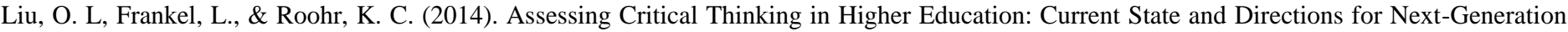
Assessment: Assessing Critical Thinking in Higher Education. ETS Research Report Series, (1), 1 - 23. https://doi.org/10.1002/ets2.12009

Mayfield, M. (2007). Thinking for yourself: Developing critical thinking skills through reading and writing (7th ed.) Thomson Wadsworth.

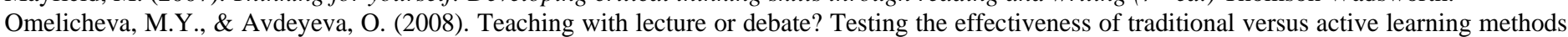
of instruction. PS: Political Science \& Politics, 41(3), 603-7. https://dx.doi.org/10.1017/S1049096508080815

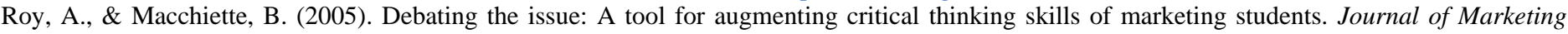
Education, 27(3), 264-276. https://doi.org/10.1177/0273475305280533

Soffel, J. (2016). What are the 21-st-century skills every students' need? World Economic Forum.

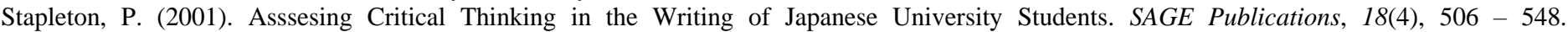
https://doi.org/10.1177/0741088301018004004

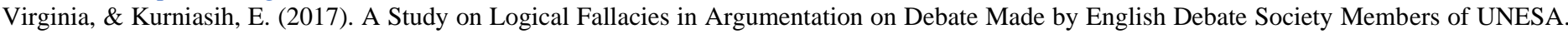
RETAIN. 5(2), 91 - 99 https://jurnalmahasiswa.unesa.ac.id/index.php/retain/article/view/19354

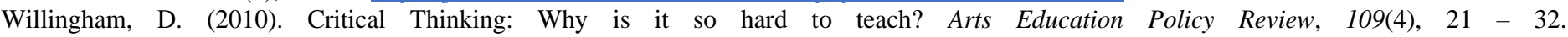
https://doi.org/10.3200/AEPR.109.4.21-32 